\title{
Appendectomy and the Risk of Colectomy in Ulcerative Colitis: A National Cohort Study
}

Pär Myrelid, Kalle Landerholm, Caroline Nordenvall, Thomas D. Pinkney and Roland Andersson

The self-archived version of this journal article is available at Linköping University Institutional Repository (DiVA):

http:// urn.kb.se/ resolve?urn=urn:nbn:se:liu:diva-140061

N.B.: When citing this work, cite the original publication.

Myrelid, P., Landerholm, K., Nordenvall, C., Pinkney, T. D., Andersson, R., (2017), Appendectomy and the Risk of Colectomy in Ulcerative Colitis: A National Cohort Study, American J ournal of

Gastroenterology, 112(8), 1311-1319. https:// doi.org/ 10.1038/ ajg.2017.183

Original publication available at:

https://doi.org/ 10.1038/ajg.2017.183

Copyright: Nature Publishing Group: Open Access Hybrid Model Option A / Wiley http:// www.nature.com/ 


\section{Appendectomy and the risk of colectomy in ulcerative colitis - a national}

\section{cohort study}

Short Title: Appendectomy for appendicitis in UC - first good, then bad

Pär Myrelid ${ }^{1,2}$, MD, PhD, Kalle Landerholm ${ }^{3,4}$ MD, PhD, Caroline Nordenvall ${ }^{5,6}, \mathrm{MD}, \mathrm{PhD}$, Thomas D Pinkney ${ }^{7}$, MBChB, MMedEd, FRCS, Roland E Andersson ${ }^{1,3}, \mathrm{MD}, \mathrm{PhD}$

${ }^{1}$ Department of Clinical and Experimental Medicine, Linköping University, ${ }^{2}$ Department of Surgery, County Council of Östergötland, Linköping, Sweden, ${ }^{3}$ Department of Surgery, County Hospital Ryhov, Jönköping, Sweden, ${ }^{4}$ Department of Surgery, Colorectal unit, Oxford University Hospitals NHS Foundation Trust, Oxford, United Kingdom ${ }^{5}$ Department of Molecular Medicine and Surgery, Karolinska Institutet, Stockholm, Sweden, ${ }^{6}$ Center for Digestive Disease, Div. of Coloproctology, Karolinska University Hospital, Stockholm, Sweden, ${ }^{7}$ Academic Department of Surgery, Division of Cancer Sciences, University of Birmingham, Birmingham, United Kingdom

Previous presentation: European Crohn's and Colitis Organisation (ECCO) $12^{\text {th }}$ congress, 15-18 February 2017, Barcelona, Spain

Grant Support: Medical Research Council of Southeast Sweden, Ihre Foundation, Bengt Ihre Research Fellowship

Correspondence: $\quad$ Pär Myrelid

Address: $\quad$ Department of Surgery, Linköping University Hospital, 58185

Linköping, Sweden.

Email: _ par.myrelid@liu.se

Phone: + +46-10-1031581, +46-70-6849994

Disclosures: We declare that there was no conflict of interests during this research performance.

Author Contributions: Study concept and design: RA, TP, PM

Acquisition of data: RA.

Analysis and interpretation of data: RA, PM

Drafting of the manuscript: PM

Critical revision of the manuscript for intellectual content: RA, KL, CN, PM, TP

Statistical Analysis: RA 


\title{
Study Highlights
}

\section{WHAT IS CURRENT KNOWLEDGE}

- Appendectomy early in life due to an inflammatory condition is associated with a lower risk of developing ulcerative colitis

2. WHAT IS NEW HERE

- Appendectomy before UC for appendicitis before 20 years of age, and at any age for diagnoses other than appendicitis, is associated with a milder UC disease course with lower risk of colectomy.

- Appendectomy before UC diagnosis for appendicitis after 20 years of age does not affect the risk of colectomy.

- Appendectomy for appendicitis in established UC appears to be associated with a worse disease course with increased rate of subsequent colectomy.

\section{Keywords}

Ulcerative colitis, Appendicitis, Appendectomy, Colectomy, Epidemiology

\author{
Abbreviations \\ UC Ulcerative Colitis \\ HR Hazard Ratio \\ IBD Inflammatory Bowel Disease \\ ICD International Classification of Diseases \\ IRR Incidence Rate Ratio
}

Word count: 3610 


\begin{abstract}

\section{Introduction}

Ulcerative colitis (UC) is a chronic inflammatory disease usually responding well to antiinflammatory drugs but many patients will still need colectomy. Appendectomy is associated with a lower risk of later developing UC. We aimed to assess the longitudinal relationship between appendectomy, appendicitis, and disease course in UC patients.
\end{abstract}

\title{
Methods
}

A national cohort of UC patients with a diagnosis in 1964-2010 was identified from the Swedish National Patient Register, which also provided information regarding appendicitis and/or appendectomy prior to or after the UC diagnosis. The risk for colectomy and UC related hospital admissions was evaluated.

\section{Results}

Among 63,711 UC patients, 2,143 had appendectomy and 7,690 underwent colectomy. Appendectomy for appendicitis before 20 years of age and for non-appendicitis at all ages prior to UC diagnosis was associated with a lower risk of colectomy (HR 0.44, 0.27-0.72 and HR 0.62, 0.43-0.90, respectively), and fewer hospital admissions (IRR 0.68, 95\% CI 0.640.73 and IRR 0.54, 0.47-0.63, respectively). Appendectomy for appendicitis after the UC diagnosis was associated with a higher risk of colectomy (HR 1.56, 1.20-2.03), while no such association was found for other pathology (HR 1.40, 0.79-2.47).

\section{Conclusions}

Appendectomy early in life and before developing UC is associated with a lower risk of colectomy as well as UC related hospital admissions. Appendectomy for appendicitis after established UC appears associated with a worse disease course, with an increased rate of subsequent colectomy. 


\section{Introduction}

Ulcerative colitis (UC) is a chronic inflammatory bowel disease (IBD) involving the colonic mucosa with a continuous spread of the inflammation from the rectum and a variable degree of proximal extension. Typically the disease starts in the late teens or early adulthood but it also occurs in children with increasing incidence over recent years ${ }^{1}$. There is no medical cure today but anti-inflammatory medication with steroids, amino salicylates and/or biologics are generally effective in controlling the disease ${ }^{2}$. Up to one-third of patients diagnosed with UC involving the colon proximal to the splenic flexure will require colectomy within 15 years of diagnosis $^{3}$. Introduction of new medical therapies could lead to a decline of colectomy rates, but data has so far been conflicting ${ }^{2}$. In a recently published report based on a national cohort in Sweden, 12\% of all UC patients had a colectomy after a mean of 4.3 years from their diagnosis ${ }^{4}$.

The etiology of IBD remains partially unclear but a number of risk factors are known. Studies have shown genetic susceptibility to be involved, as well as an impaired intestinal permeability and an inappropriate immune response to gut microbiota ${ }^{1,2}$. Appendectomy due to an inflammatory process like appendicitis or mesenteric lymphadenitis have been shown to be inversely associated with the risk of developing $\mathrm{UC}^{5-7}$. The appendix may be of significance also in established UC, where a peri-appendiceal orifice inflammation has been suggested to be associated with a milder form of UC although any effect on the colectomy rate is unclear ${ }^{8}$. It has been proposed that the inverse association between appendectomy and ulcerative colitis may be explained by an immunomodulating effect of the appendectomy. This has raised the question of appendectomy as a possible therapeutic option for UC ${ }^{9-14}$. This hypothesis is currently being evaluated in an on-going international trial ${ }^{15}$.

The present study aimed to assess the relationship between appendectomy and disease activity including progression to colectomy in UC patients, compared with those who did not undergo appendectomy. A second aim was to clarify whether UC disease activity is 
associated more strongly with appendicitis (inflammation), or with appendectomy (operation).

\section{Method}

A unique personal identity number is assigned to all permanent residents in Sweden. This identity number enables follow-up of diagnoses for diseases, performed surgeries, causes of death, and migration in the National Patient Register in Sweden.

A cohort of all patients with a diagnosis of IBD in Sweden between $1^{\text {st }}$ of January 1964 and $31^{\text {st }}$ of December 2010 was identified from the National Patient Register. For this study we selected all patients with a diagnosis of UC (ICD7 572.20, 572.21, 578.03; ICD8 563.10, 569.02; ICD9 556*; ICD10 K51*). As the type of IBD diagnosis may change over time the last registered diagnosis was used as the true diagnosis for patients having multiple registrations with different IBD diagnoses. The date of the first registered IBD diagnosis in the register was deemed as the date of the onset of the disease.

From this cohort of UC patients, we identified all patients that had been operated with appendectomy (operation code 4510, 4511, 0058, JEA00, JEA01 or JEA10) for appendicitis (ICD7 550*, 551,99, 552*; ICD8 540*, 541,99, 542*; ICD9 540*, 541*, 542*; ICD10 K35*, K36*, K37*) or negative appendectomy, represented by diagnostic codes for nonspecific abdominal pain (ICD7 793,69; ICD8 785,51, 785,59; ICD9 789A; ICD10 R10*) or mesenteric lymphadenitis (ICD7 468,10; ICD8 289,20; ICD9 289C, 785G; ICD10 I88.0, R59*), and for other diagnoses (representing a large number of diagnoses). We also identified patients that had been operated with subtotal colectomy or proctocolectomy with or without restorative surgery (operation code 4650-4654, JFH00-JFH40), or had had multiple segmental colonic resections eventually adding up to a subtotal colectomy. The last operation in this chain of surgeries was taken as the date of colectomy. 


\section{Statistical Analysis}

Three subsets of UC patients were identified: patients never undergoing appendectomy, patients having appendectomy before the diagnosis of UC, and patients having appendectomy after the UC diagnosis. The risk of colectomy was analysed with survival analytic technique with Kaplan-Meier curves and log rank test, and uni- and multivariable Cox regression analysis. We estimated the incidence rate of the number of admissions for UC during the follow up period and made comparisons using incidence rate ratio (IRR) derived from Poisson regression analysis.

The impact of appendectomy prior to the UC diagnosis on the rate of colectomy and UC related admissions was estimated by contrasting patients with non-appendectomy, appendectomy for appendicitis before and after age 20 years, and appendectomy for other diagnoses. In this analysis follow up started on the day of first UC diagnosis and ended on the date of colectomy, the date of eventual appendectomy after UC diagnosis, death, emigration, or $31^{\text {st }}$ of December 2010, whichever came first.

A case-control design was used to analyse the impact of appendectomy after the UC diagnosis on the UC disease course. UC patients that did not have appendectomy (controls) were randomly matched with the patients that had appendectomy after the UC diagnosis (cases). To obtain similar follow up time this matching was done within strata of each decade of the study period. The interval between the UC diagnosis and the date of appendectomy was determined for the cases and the date corresponding to the same interval after the UC diagnosis was determined for the matched controls. Follow up started on the day of appendectomy for the case and on the date of the corresponding interval after the UC diagnosis for the matched case-control datasets. In both groups follow up ended on the date of colectomy, death, emigration, or $31^{\text {st }}$ of December 2010, whichever came first. 
Differences between groups were analyzed with Chi2-, t-, Wilcoxon rank-sum and Kruskal Wallis test as appropriate. The analyses were carried out with Stata 13 (StataCorp, TX, USA). Statistical tests were 2-sided, and statistical significance was set at the 0.05 level. The study was approved by the Linköping Regional Ethics Review Board (Dnr 2011/419-31). 


\section{Results}

During the study period 1964 to 2010 a total of 63,711 patients were diagnosed with UC, after exclusion of 84 registration errors. In this cohort, 1,537 patients had been operated with appendectomy prior to and 603 after the UC diagnosis (Table 1, Figure 1).

\section{Appendectomy prior to the development of UC}

The patients with appendectomy prior to the UC diagnosis had similar sex distribution but were older at the UC diagnosis than UC patients without appendectomy before UC diagnosis. Patients with appendectomy before UC diagnosis also had a lower risk of colectomy than the remainder of the cohort (Tables 1, 2 and 3, Figure 2). However, the lower risk of colectomy was seen only in patients with appendectomy for appendicitis before 20 years of age (HR 0.44, (95\% CI 0.27-0.72), and not if operated after that age (HR 0.97, 95\% CI 0.80-1.18)

(Table 3). Appendectomy for other reasons than appendicitis was also associated with a lower risk of colectomy regardless of the age at appendectomy (HR 0.62, 95\% CI 0.43-0.90). The difference in risk was present already immediately after the UC diagnosis and continued to increase during the 20 years of follow up.

Patients with appendectomy before the UC diagnosis also experienced fewer hospital admissions due to UC during follow up (IRR 0.68, 95\% CI 0.64-0.73) (Tables 1 and 4). This inverse association was strongest after appendectomy for other diagnoses than appendicitis, but present also after appendectomy for appendicitis regardless of age (Table 4).

\section{Appendectomy in established UC}

Some 603 patients (1.0\% of the total cohort) underwent appendectomy after the date of diagnosis of UC. These patients had the same sex distribution as the non-appendectomy controls, but were younger at UC diagnosis, at the start of follow up and at colectomy (Table 1). A majority (463 (76.4 \%)) had a discharge diagnosis of appendicitis after the operation (Figure 1). These patients, undergoing appendectomy due to appendicitis in the context of 
established UC, experienced an increased risk of colectomy (HR 1.56, 95\% CI 1.20-2.03), while no such association was found among those without appendicitis (HR 1.40, 95\% CI 0.79-2.47) (Figure 2, tables 2 and 3). This higher risk for colectomy following appendectomy for appendicitis remained after further adjustment for the differences in age at the UC diagnosis, interval from UC diagnosis until appendectomy and year of appendectomy (HR 1.36, 95\% CI 1.05-1.77).

Overall, patients undergoing appendectomy for any reason after their UC diagnosis showed lower rates of UC related hospital admission. The incidence rate was the same irrespective of the diagnosis at appendectomy but the difference was statistically significant only for appendectomy for appendicitis (IRR 0.87, 95\% CI 0.80-0.94) (Table 4).

Female gender and late diagnosis of UC (patients above the median age 42 years at UC diagnosis) was associated with a decreased overall risk of colectomy and fewer hospital admissions due to UC, regardless of appendectomy prior to or after UC diagnosis (Tables 3 and 4). 


\section{Discussion}

This is the first study on the possible effect of appendectomy on the risk of colectomy in an unselected national cohort of UC patients. We found associations that were dependent on if appendectomy was performed for appendicitis or not, the age at appendectomy for appendicitis and if the appendectomy was performed before or after the patients had developed UC.

The risk for colectomy was lower in patients not yet diagnosed with UC and operated for appendicitis before the age of 20 years, while no such effect was found if they had their appendectomy after that age. We also found a lower frequency of hospital admissions due to UC in patients operated with appendectomy before the UC diagnosis, regardless of pathology. In patients having appendectomy after established UC we found a worse prognosis with a higher risk of colectomy. This association was significant only for appendectomy for appendicitis but a similar tendency was also seen after appendectomy for other diagnoses.

Previous studies have reported a decreased risk of developing UC, as well as a delayed onset of the disease, in patients operated for appendicitis before age 20 years and in patients operated for mesenteric lymphadenitis ${ }^{5,6,13}$. A recent Danish study also found a lower risk of UC in individuals with a first-degree relative with appendicitis at young age ${ }^{16}$. Our results are supplementary to these earlier reports, which taken together suggest a reduced risk in developing UC in patients operated for appendicitis before age 20 years, and a milder course of UC in patients operated for appendicitis after age 20 years in already established UC. These results strengthen the hypothesis that appendicitis and UC may be related to different genetic, immunological or environmental factors. In concordance with the previous studies we also did not see any difference in the risk of colectomy in patients that had appendectomy for appendicitis at an age over 20 years. These findings do not support the hypothesis of an immune modulating effect of the appendectomy itself. On the other hand, patients appendectomised for other reasons than appendicitis, irrespective of age at appendectomy, 
had a lower risk of colectomy which could speak in favor of either a genetic predisposition or an immune modulating effect after all.

The previously mentioned studies have shown a reduced risk of developing UC in patients operated with appendectomy for mesenteric lymphadenitis but not for other diagnoses. In the present study these diagnoses were merged in the analyses due to the small number. We found that appendectomy for other diagnoses was associated with a milder course of UC if performed before the UC diagnosis, but a worse prognosis if performed after the UC diagnosis was established. One potential explanation to the worse prognosis after appendectomy in patients with already established UC could be that a more aggressive colitis is associated both with an inherent high risk of colectomy and with a higher risk for appendectomy, either by inducing appendicitis or by necessitating abdominal exploration and appendectomy. Mechanisms by which active UC could bring about appendicitis could include downstream proximal constipation, or in patients with pancolitis possibly extension of inflammation to the appendix. The effect remained however unabated during follow up after appendectomy which does not support these hypotheses. Alternatively, it cannot be ruled out that appendectomy indeed has a causal negative effect on the UC disease course quite opposite to current beliefs.

The cases and controls in this analysis were matched on year of appendectomy and the follow up was started on the date of appendectomy in the cases. For the controls the follow up started at the same time duration after the UC diagnosis as the matched cases. However, the appendectomy cases were younger at UC diagnosis, at appendectomy and at colectomy. Adjustment for these potential confounding factors only changed the results marginally.

As previously described by others, the rate of colectomy was high early ${ }^{17}$ after the UC diagnosis (Table 1, Figure 2). Most of the appendectomies in established UC occurred after 
this high-risk period for colectomy as the mean interval between the UC diagnosis and the appendectomy was 7.1 years. Similarly, many of the colectomies among the patients with established UC diagnosis going through appendectomy for other pathology than appendicitis were done shortly after the appendectomy (Figure 3). As previously discussed this could be due to a subset of patients with a more aggressive or active UC misdiagnosed as possible appendicitis subsequently with a higher risk of colectomy. Later on however there was no difference in need of colectomies compared with those without appendectomy (Table 2-3, Figure 3).

The effect of appendectomy in patients with already established UC has been studied in a number of case series with diverging results ${ }^{9-14}$. Some studies have focused upon the long term outcome of UC if ever appendectomized whereas other studies have focused rather on appendectomy itself during active disease ${ }^{9-12}$. In a study by Bolin et al, an improved outcome was found in 27 of 30 patients with ulcerative proctitis ${ }^{9}$. Twelve of the patients (40\%) had a complete remission by one year and were able to withdraw all medication and still be in remission after a further 9 (range 6-25) months. Two small studies, so far only reported as abstracts, found early response in $53 \%$ (16/30) and $93 \%$ (14/15), respectively after appendectomy due to chronically active $U^{18,19}$. Complete remission was seen in $30-60 \%$ but in the latest study by Sahami et al the one year data showed a deterioration at one year but still with $47 \%$ responders and $17 \%$ remaining in complete remission ${ }^{18}$. Selby et al reported that appendectomy may delay onset of UC but found no effect on the course of the disease ${ }^{13}$. This was also the finding in a recent report from Korea ${ }^{11}$. In a nested case control study, no influence was found by appendectomy on disease extent at UC diagnosis, rates of medication use or proximal disease extension. Nor was any difference in the colectomy rates seen at 10 or 20 year from IBD diagnosis. The need of hospital admissions was also evaluated and no correlation to appendectomy was seen. The same was shown in a previous study from 
Denmark $^{20}$. The most recent report, which also included a meta-analysis, found no signs of a beneficial effect of appendectomy on the course of $\mathrm{UC}^{14}$.

Appendicitis has also been studied in a number of other inflammatory conditions, within as well as outside of the gastrointestinal tract. Most reports have shown an inverse association between a previous appendicitis and different inflammatory conditions, e.g. coeliac disease $\mathrm{e}^{21}$, primary sclerosing cholangitis ${ }^{13}$ and ankylosing spondylitis ${ }^{22}$. By contrast, patients with appendicitis were found to have an increased risk of rheumatoid arthritis, ${ }^{23,}{ }^{24}$ while other reports found no such correlation ${ }^{25,26}$. The immunology of the appendix is far from clear. The immunological response could possibly be altered by appendicitis taking place in a younger and immunologically less developed individual, but not in an older and immunologically more mature individual ${ }^{27}$.

Cheluvappa et al found appendectomy in a murine model to induce suppression of autophagy in the colon ${ }^{28}$ and Harnoy et al found histological improvement in a similar murine model of appendicitis, more pronounced in younger mice than older ${ }^{29}$. This is possibly related to upand downregulation of genes associated with a diminished antigen processing leading to less immunity between microbes and self-antigens thus having an anti-inflammatory effect on the colitis $^{30}$. In this model there are some major limitations as it included construction of an appendix of a caecal lymphoid patch as well as an obstruction of this appendix why this should be interpreted with caution. Other possible mechanisms are an increase in regulatory $\mathrm{T}$ cells (FoxP3+CD25+) during appendicitis preventing auto-reactivity as well as an increase of CD5+ B lymphocytes, cells decreased in number in UC patients, and the high level of CD19+ $\mathrm{B}$ cells in the normal appendix (and even higher levels in the inflamed appendix) ${ }^{28}$. The high levels of CD19+ B cells could be a marker of the appendix being important in the maturation of B cells. 
Appendiceal orifice inflammation in UC patients has also been studied recently. Some authors proposed a milder form of UC in the presence of appendiceal orifice inflammation, whereas others found the opposite including an increased risk of later developing pouchitis after restorative proctocolectomy ${ }^{8}$. One major concern is the finding by Harnoy et al of an increased risk of developing colonic mucosal dysplasia in mice with an appendectomy in a chemically induced colitis model without having an experimental appendicitis ${ }^{29}$. In the same report they made a retrospective analysis of a patient cohort which confirmed an association of appendectomy prior to a diagnosis of UC as an independent risk factors for colonic neoplasia ${ }^{29}$. This particular area requires further studies.

The present study is by far the largest reported cohort study, based on over 63,000 patients followed for over 600,000 person years. Using a population-based cohort from a nationwide registry has the advantages of a large sample size with long follow up and the elimination of referral bias but with the limitation of restricted amount of detailed data available for each patient.

Register based studies have some inherent weaknesses. Before 2001 the date of the UC diagnosis is based only on hospital admissions. This means that milder colitis may have been missed or that their true date of diagnosis was earlier than recorded before 2000. A sensitivity analysis of the patients included from 2001-2010 did not give reason to change the reported results. We have found a few, less than 100, apparent registration errors which should not give any substantial bias, but it is possible that such errors are more frequent in subsamples. The National Patient Registry was evaluated in two recent studies to have a positive predictive value between 85 and $95 \%$ regarding the validity of diagnoses and procedures and between 72 and $83 \%$ for IBD diagnoses, as some patients are misclassified, or changes between UC and Crohn's disease over time ${ }^{31,32}$. A validation study of appendicitis diagnosis after appendectomy, focusing on the correspondence between discharge diagnosis and histopathology report, showed a validity of $91 \%$, with $10 \%$ false positive diagnoses and $6 \%$ 
false negative diagnoses. The most probable consequence of these errors to the present study would be a dilution of any associations as they seem unlikely to be differential ${ }^{33}$. The validity of the information on appendectomy, colectomy and admissions are probably higher. It seems unlikely that there should be any differential misclassification in this regard.

\section{Conclusion}

Appendectomy has previously been shown to be associated with a lower risk of developing UC as well as a delayed onset of the disease. The present report provides complementary information to current knowledge as it shows that appendectomy prior to the development of UC is also associated with a less aggressive disease as demonstrated by a long term lower risk of colectomy and hospital admissions. This result gives further support to the hypothesis that appendicitis early in life and UC are inversely related to through genetic factors or immunologic responses. Somewhat contradictive we found an association of a long term worse prognosis of UC in patients that had appendectomy after the diagnosis of UC was established. These results motivate further research into the genetic and immunologic links between appendectomy, appendicitis and UC. 


\section{References}

1. Malmborg $\mathrm{P}$, Hildebrand $\mathrm{H}$. The emerging global epidemic of paediatric inflammatory bowel disease--causes and consequences. J Intern Med 2016;279:241-58.

2. Annese V, Duricova D, Gower-Rousseau C, et al. Impact of New Treatments on Hospitalisation, Surgery, Infection, and Mortality in IBD: a Focus Paper by the Epidemiology Committee of ECCO. J Crohns Colitis 2016;10:216-25.

3. Farmer RG, Easley KA, Rankin GB. Clinical patterns, natural history, and progression of ulcerative colitis. A long-term follow-up of 1116 patients. Dig Dis Sci 1993;38:1137-46.

4. Abdalla M, Landerholm K, Andersson P, et al. Risk of developing rectal cancer after colectomy in ulcerative colitis patients - a national cohort study. Clinical Gastroenterology \& Hepatology 2017; In press.

5. Andersson RE, Olaison G, Tysk C, et al. Appendectomy and protection against ulcerative colitis. N Engl J Med 2001;344:808-14.

6. Frisch M, Pedersen BV, Andersson RE. Appendicitis, mesenteric lymphadenitis, and subsequent risk of ulcerative colitis: cohort studies in Sweden and Denmark. BMJ 2009;338:b716.

7. Russel MG, Dorant E, Brummer RJ, et al. Appendectomy and the risk of developing ulcerative colitis or Crohn's disease: results of a large case-control study. South Limburg Inflammatory Bowel Disease Study Group. Gastroenterology 1997;113:377-82.

8. Park SH, Loftus EV, Jr., Yang SK. Appendiceal skip inflammation and ulcerative colitis. Dig Dis Sci 2014;59:2050-7.

9. Bolin TD, Wong S, Crouch R, et al. Appendicectomy as a therapy for ulcerative proctitis. Am J Gastroenterol 2009;104:2476-82.

10. Järnerot $G$, Andersson M, Franzén L. Laparoscopic appendectomy in patients with refractory ulcerative colitis. Gastroenterology 2001;120:1562-3.

11. Lee HS, Park SH, Yang SK, et al. Appendectomy and the clinical course of ulcerative colitis: a retrospective cohort study and a nested case-control study from Korea. J Gastroenterol Hepatol 2015;30:470-7.

12. Jo Y, Matsumoto T, Yada S, et al. Histological and immunological features of appendix in patients with ulcerative colitis. Dig Dis Sci 2003;48:99-108.

13. Selby WS, Griffin S, Abraham N, et al. Appendectomy protects against the development of ulcerative colitis but does not affect its course. Am J Gastroenterol 2002;97:2834-8.

14. Parian A, Limketkai B, Koh J, et al. Appendectomy does not decrease the risk of future colectomy in UC: results from a large cohort and meta-analysis. Gut 2016.

15. Gardenbroek TJ, Pinkney TD, Sahami S, et al. The ACCURE-trial: the effect of appendectomy on the clinical course of ulcerative colitis, a randomised international multicenter trial (NTR2883) and the ACCURE-UK trial: a randomised external pilot trial (ISRCTN56523019). BMC Surg 2015;15:30.

16. Nyboe Andersen N, Gortz S, Frisch M, et al. Reduced risk of UC in families affected by appendicitis: a Danish national cohort study. Gut 2016.

17. Kaplan GG, Seow CH, Ghosh S, et al. Decreasing colectomy rates for ulcerative colitis: a population-based time trend study. Am J Gastroenterol 2012;107:1879-87.

18. Sahami S, Buskens CJ, Winter DC, et al. Therapy refractory UC patients may benefit from appendectomy; early resluts from the PASSION study, In UEG Week, Vienna, United European Gastroenterology Journal 4(5S), 2016.

19. Radford-Smith GL, Eri R, Lumley J, et al. 'Targeted' appendectomy for patients with refractory ulcerative colitis, Journal of Gastroenterology and Hepatology (2003) 18 (Suppl.), 2003.

20. Hallas J, Gaist D, Vach W, et al. Appendicectomy has no beneficial effect on admission rates in patients with ulcerative colitis. Gut 2004;53:351-4.

21. Ludvigsson JF, Askling J, Ekbom A, et al. Diagnosis underlying appendectomy and coeliac disease risk. Dig Liver Dis 2006;38:823-8. 
22. Lindström $\mathrm{U}$, Exarchou $\mathrm{S}$, Lie $\mathrm{E}$, et al. Infections of the gut, urogenital and respiratory tract and appendicitis during childhood, and the risk of developing ankylosing spondylitis., In EULAR, London, June 8-11, 2016.

23. Gottlieb NL, Page WF, Appelrouth DJ, et al. Antecedent tonsillectomy and appendectomy in rheumatoid arthritis. J Rheumatol 1979;6:316-23.

24. Tzeng YM, Kao LT, Kao S, et al. An appendectomy increases the risk of rheumatoid arthritis: a five-year follow-up study. PLoS One 2015;10:e0126816.

25. Linos AD, O'Fallon WM, Worthington JW, et al. The effect of tonsillectomy and appendectomy on the development of rheumatoid arthritis. J Rheumatol 1986;13:707-9.

26. Moens HB, Corstjens A, Boon C. Rheumatoid arthritis is not associated with prior tonsillectomy or appendectomy. Clin Rheumatol 1994;13:483-6.

27. Watson Ng WS, Hampartzoumian T, Lloyd AR, et al. A murine model of appendicitis and the impact of inflammation on appendiceal lymphocyte constituents. Clin Exp Immunol 2007;150:169-78.

28. Cheluvappa R, Luo AS, Grimm MC. Autophagy suppression by appendicitis and appendectomy protects against colitis. Inflamm Bowel Dis 2014;20:847-55.

29. Harnoy $Y$, Bouhnik $Y$, Gault N, et al. Effect of appendicectomy on colonic inflammation and neoplasia in experimental ulcerative colitis. Br J Surg 2016.

30. Kooij IA, Sahami S, Meijer SL, et al. The immunology of the vermiform appendix: a review of the literature. Clinical \& Experimental Immunology 2016:n/a-n/a.

31. Ludvigsson JF, Andersson E, Ekbom A, et al. External review and validation of the Swedish national inpatient register. BMC Public Health 2011;11:450.

32. Jakobsson GL, Sternegard E, Olen O, et al. Validating inflammatory bowel disease (IBD) in the Swedish National Patient Register and the Swedish Quality Register for IBD (SWIBREG). Scand J Gastroenterol 2017;52:216-221.

33. Andersson R, Hugander A, Thulin A, et al. Indications for operation in suspected appendicitis and incidence of perforation. BMJ 1994;308:107-10. 


\section{Tables and Figures}

\section{Figure 1}

Distribution of patients according to history of appendectomy before and after the UC diagnosis, showing number of admissions for UC and colectomies during follow up. Points and arrowheads represent start and end of follow up, respectively. A matched case-control design was used for the analyses of the effect of appendectomy after the UC diagnosis. The follow up started at the same interval after the UC diagnosis for the controls as their matched cases.

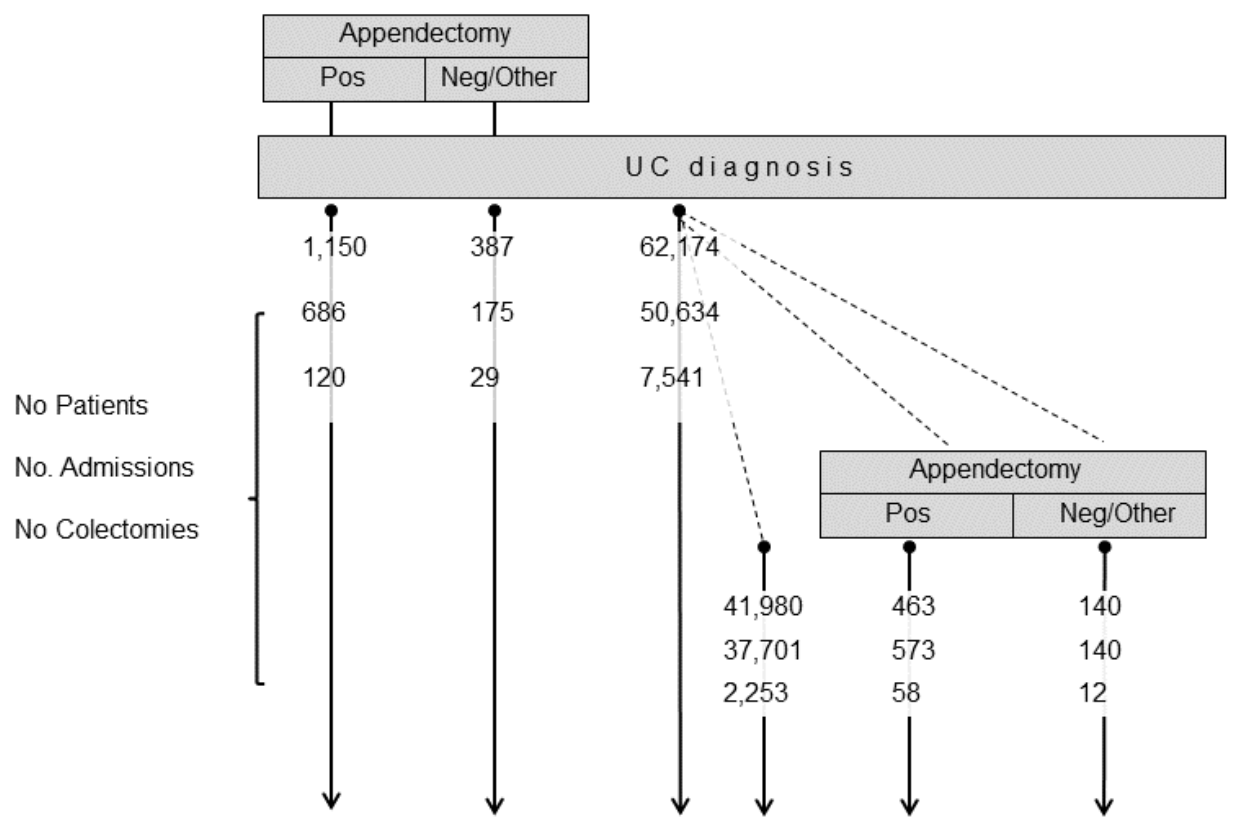




\section{Figure 2}

Cumulated proportion of patients having colectomy by appendectomy status before UC diagnosis. Separate curves are given for patients having appendectomy for appendicitis, divided into appendectomy before and after age 20 years, and appendectomy for other diagnoses

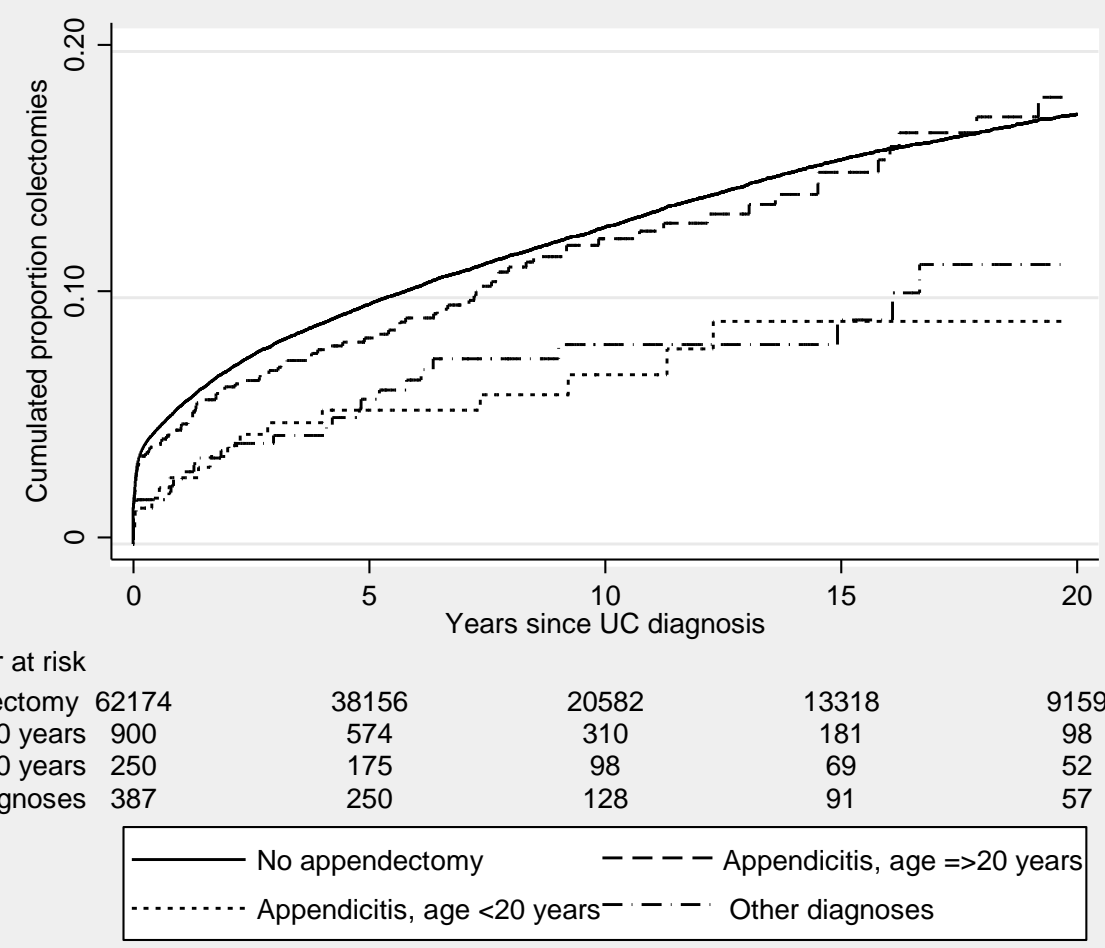




\section{Figure 3}

Cumulated proportion of patients having colectomy by appendectomy exposure after UC diagnosis. The pathology at appendectomy is divided into appendicitis and other diagnoses. Follow up for patients without appendectomy (controls) starts at day of appendectomy in matched sets of cases and controls.

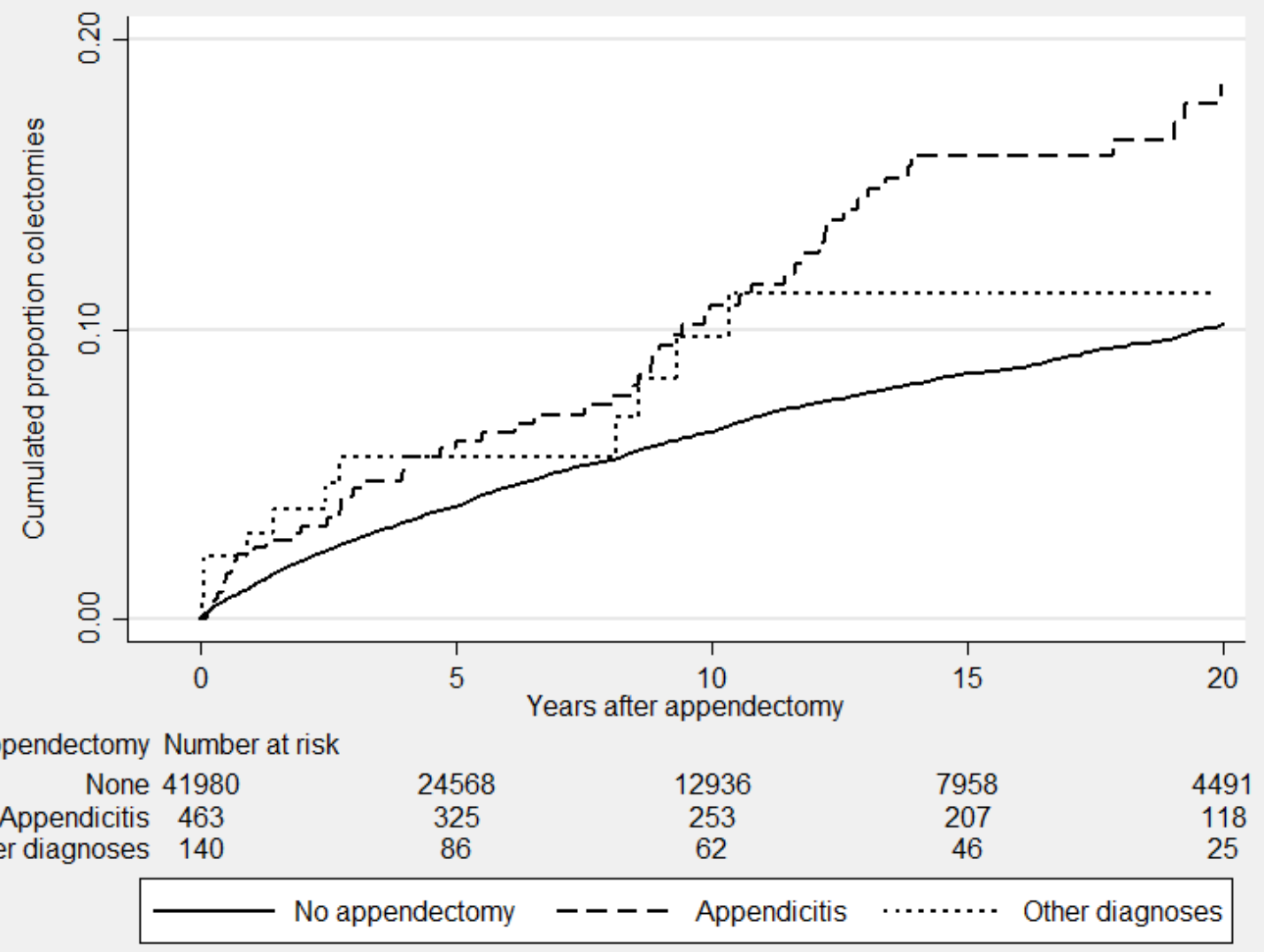




\section{Table 1}

Demographics for the cohort of UC patients. Follow up start at the date of the UC diagnosis for the comparison of appendectomy before the UC diagnosis, and at the date of appendectomy for the comparison of appendectomy after the UC diagnosis.

\begin{tabular}{|c|c|c|c|c|c|c|}
\hline & \multicolumn{3}{|c|}{ Appendectomy prior to UC diagnosis } & \multicolumn{3}{|c|}{ Appendectomy after UC diagnosis } \\
\hline & No & Yes & p-value & No & Yes & $p$-value \\
\hline Number & 62,174 & 1,537 & & 41,980 & 603 & \\
\hline Males (\%) & $32,582(53 \%)$ & $796(52 \%)$ & 0.394 & $22,148(53 \%)$ & $300(50 \%)$ & 0.142 \\
\hline $\begin{array}{l}\text { Appendicitis at } \\
\text { appendectomy (\%) }\end{array}$ & NA & $\begin{array}{l}1,150 \\
(75 \%)\end{array}$ & & NA & $463(77 \%)$ & \\
\hline \multicolumn{7}{|l|}{ Mean age, years (SD) } \\
\hline at appendectomy & NA & $32.2(16.3)$ & & $46.8(19.2)$ & $40.6(17.0)$ & $<0.001$ \\
\hline at UC diagnosis & $44.6(20.3)$ & $45.9(17.4)$ & 0.002 & $42.4(19.1)$ & $33.6(16.9)$ & $<0.001$ \\
\hline at colectomy & $43.2(17.2)$ & $44.1(14.7)$ & 0.280 & $44.3(14.2)$ & $38.4(14.1)$ & 0.035 \\
\hline $\begin{array}{l}\text { Mean (SD) interval } \\
\text { between UC diagnosis } \\
\text { and appendectomy, } \\
\text { years }\end{array}$ & NA & $13.7(10.2)$ & & NA & $7.1(6.8)$ & \\
\hline Follow up, years & 603,462 & 15,047 & & 362,487 & 7,598 & \\
\hline Colectomy (\%) & $7,541(12.1)$ & $149(9.7)$ & 0.004 & $2,253(5.4 \%)$ & $70(11.6)$ & $<0.001$ \\
\hline Admissions due to UC & 50,634 & 861 & & 37,701 & 713 & \\
\hline Admissions per year & 0.084 & 0.057 & $<0.001$ & 0.104 & 0.094 & 0.006 \\
\hline Incidence Rate ratio & \multicolumn{2}{|c|}{$0.68(0.64-0.73)$} & $<0.001$ & \multicolumn{2}{|c|}{$0.90(0.84-0.97)$} & 0.006 \\
\hline
\end{tabular}


Table 2

Cumulated proportion of patients having colectomy by appendectomy status before and after

UC diagnosis. Separate analyses for age groups and indication for appendectomy.

\begin{tabular}{|c|c|c|c|c|}
\hline & \multicolumn{4}{|c|}{ Cumulated proportion with colectomy } \\
\hline & 1 year & 5 year & 10 year & 20 year \\
\hline \multicolumn{5}{|l|}{ No appendectomy } \\
\hline & $0.06(0.05-0.06)$ & $0.10(0.09-0.10)$ & $0.13(0.12-0.13)$ & $0.17(0.17-0.18)$ \\
\hline \multicolumn{5}{|c|}{ Appendectomy for appendicitis prior to UC diagnosis } \\
\hline at age $<20$ years & $0.02(0.01-0.05)$ & $0.05(0.03-0.09)$ & $0.07(0.04-0.11)$ & $0.09(0.05-0.15)$ \\
\hline at age $\geq 20$ years & $0.04(0.03-0.06)$ & $0.08(0.06-0.10)$ & $0.12(0.10-0.15)$ & $0.18(0.14-0.22)$ \\
\hline \multicolumn{5}{|c|}{ Appendectomy for other diagnoses prior to UC diagnosis } \\
\hline at age $<20$ years & $0.01(0.00-0.06)$ & $0.06(0.03-0.11)$ & $0.07(0.03-0.13)$ & $0.11(0.06-0.22)$ \\
\hline at age $\geq 20$ years & $0.03(0.01-0.06)$ & $0.06(0.03-0.10)$ & $0.09(0.05-0.14)$ & $0.11(0.06-0.18)$ \\
\hline \multicolumn{5}{|c|}{ No appendectomy or appendectomy after UC diagnosis } \\
\hline No appendectomy & $0.01(0.01-0.01)$ & $0.04(0.04-0.04)$ & $0.06(0.06-0.07)$ & $0.10(0.10-0.11)$ \\
\hline Appendicitis & $0.02(0.01-0.04)$ & $0.06(0.04-0.09)$ & $0.11(0.08-0.15)$ & $0.18(0.14-0.24)$ \\
\hline Other diagnoses & $0.03(0.01-0.08)$ & $0.06(0.03-0.11)$ & $0.10(0.05-0.18)$ & $0.11(0.06-0.20)$ \\
\hline
\end{tabular}

Values within parentheses represent $95 \% \mathrm{Cl}$. 
Table 3

Uni- and multivariable proportional hazards regression for risk factors of colectomy stratified by age at appendectomy ( $<20$ and $\geq 20$ years) because of multicollinearity.

\begin{tabular}{|c|c|c|c|c|}
\hline \multirow{2}{*}{ Variable } & \multicolumn{2}{|c|}{ Univariate analysis } & \multicolumn{2}{|c|}{ Multivariate analysis } \\
\hline & HR $(95 \% \mathrm{Cl})$ & p-value & HR $(95 \% \mathrm{Cl})$ & p-value \\
\hline \multicolumn{5}{|c|}{ A. Appendectomy status before UC diagnosis } \\
\hline \multicolumn{5}{|l|}{ Gender } \\
\hline Men & Ref & & Ref & \\
\hline Women & $0.76(0.72-0.79)$ & $<0.001$ & $0.76(0.73-0.79)$ & $<0.001$ \\
\hline \multicolumn{5}{|l|}{ Age at UC diagnosis ${ }^{1}$} \\
\hline$\leq 42$ years & Ref & & Ref & \\
\hline$>42$ years & $0.74(0.71-0.78)$ & $<0.001$ & $0.74(0.71-0.78)$ & $<0.001$ \\
\hline \multicolumn{5}{|c|}{ Appendectomy status before UC diagnosis } \\
\hline No appendectomy & Ref & & Ref & \\
\hline $\begin{array}{l}\text { Appendectomy for appendicitis } \\
\text { at age }<20 \text { years }\end{array}$ & $0.48(0.29-0.79)$ & 0.004 & $0.44(0.27-0.72)$ & 0.001 \\
\hline $\begin{array}{l}\text { Appendectomy for appendicitis } \\
\text { at age } \geq 20 \text { years }\end{array}$ & $0.95(0.78-1.16)$ & 0.622 & $0.97(0.80-1.18)$ & 0.748 \\
\hline $\begin{array}{l}\text { Appendectomy for other } \\
\text { diagnoses at any age }\end{array}$ & $0.60(0.42-0.87)$ & 0.006 & $0.62(0.43-0.90)$ & 0.011 \\
\hline \multicolumn{5}{|c|}{ B. Appendectomy exposure after UC diagnosis } \\
\hline \multicolumn{5}{|l|}{ Gender } \\
\hline Men & Ref & & Ref & \\
\hline Women & $0.74(0.69-0.81)$ & $<0.001$ & $0.75(0.69-0.81)$ & $<0.001$ \\
\hline \multicolumn{5}{|l|}{ Age at UC diagnosis ${ }^{1}$} \\
\hline$\leq 42$ years & Ref & & Ref & \\
\hline$>42$ years & $0.63(0.58-0.69)$ & $<0.001$ & $0.64(0.58-0.69)$ & $<0.001$ \\
\hline \multicolumn{5}{|c|}{ Appendectomy exposure after UC diagnosis } \\
\hline No appendectomy & Ref & & Ref & \\
\hline Appendectomy for appendicitis & $1.73(1.33-2.24)$ & $<0.001$ & $1.56(1.20-2.03)$ & 0.001 \\
\hline $\begin{array}{l}\text { Appendectomy for other } \\
\text { diagnoses }\end{array}$ & $1.36(0.77-2.39)$ & 0.291 & $1.40(0.79-2.47)$ & 0.244 \\
\hline
\end{tabular}

\footnotetext{
${ }^{1}$ Age at UC diagnosis divided in two groups by median age 42 years.
} 
Table 4

Comparison of admission to hospital for ulcerative colitis during follow up, in relation to sex, age at UC diagnosis, appendectomy status and diagnosis at appendectomy. Uni- and multivariate estimates of Incidence Rate Ratios through Poisson regression are displayed.

\begin{tabular}{|c|c|c|c|c|}
\hline \multirow{2}{*}{\begin{tabular}{|l|} 
Variable \\
\end{tabular}} & \multicolumn{2}{|c|}{ Univariate analysis } & \multicolumn{2}{|c|}{ Multivariate analysis } \\
\hline & IRR (95\% CI) & p-value & IRR (95\% CI) & p-value \\
\hline \multicolumn{5}{|c|}{ A. Appendectomy status before UC diagnosis } \\
\hline \multicolumn{5}{|l|}{ Gender } \\
\hline Men & Ref & & Ref & \\
\hline Women & $0.91(0.90-0.93)$ & $<0.001$ & $0.91(0.88-0.93)$ & $<0.001$ \\
\hline \multicolumn{5}{|l|}{ Age at UC diagnosis } \\
\hline$\leq 42$ years & Ref & & Ref & \\
\hline$>42$ years & $0.79(0.78-0.81)$ & $<0.001$ & $0.79(0.78-0.81)$ & $<0.001$ \\
\hline \multicolumn{5}{|c|}{ Appendectomy status before UC diagnosis } \\
\hline No appendectomy & Ref & & Ref & \\
\hline $\begin{array}{l}\text { Appendectomy for appendicitis } \\
\text { at age }<20 \text { years }\end{array}$ & $0.74(0.68-0.81)$ & $<0.001$ & $0.75(0.69-0.82)$ & $<0.001$ \\
\hline $\begin{array}{l}\text { Appendectomy for appendicitis } \\
\text { at age } \geq 20 \text { years }\end{array}$ & $0.70(0.60-0.81)$ & $<0.001$ & $0.65(0.56-0.76)$ & $<0.001$ \\
\hline $\begin{array}{l}\text { Appendectomy for other } \\
\text { diagnoses at any age }\end{array}$ & $0.54(0.47-0.63)$ & $<0.001$ & $0.54(0.46-0.62)$ & $<0.001$ \\
\hline
\end{tabular}

\section{B. Appendectomy exposure after UC diagnosis}

\begin{tabular}{|c|c|c|c|c|}
\hline \multicolumn{5}{|l|}{ Gender } \\
Men & Ref & & Ref & \\
\hline Women & $0.95(0.93-0.97)$ & $<0.001$ & $0.95(0.93-0.97)$ & $<0.001$ \\
\hline
\end{tabular}

Age at UC diagnosis

\begin{tabular}{|l|c|c|c|c|}
\hline$\leq 42$ years & Ref & & Ref & \\
\hline$>42$ years & $0.79(0.78-0.81)$ & $<0.001$ & $0.79(0.77-0.81)$ & $<0.001$ \\
\hline
\end{tabular}

Appendectomy exposure after UC diagnosis

\begin{tabular}{|l|c|c|c|c|}
\hline No appendectomy & Ref & & Ref & \\
\hline Appendectomy for appendicitis & $0.91(0.84-0.99)$ & 0.026 & $0.87(0.80-0.94)$ & 0.001 \\
\hline $\begin{array}{l}\text { Appendectomy for other } \\
\text { diagnoses }\end{array}$ & $0.87(0.74-1.03)$ & 0.102 & $0.86(0.73-1.01)$ & 0.069 \\
\hline
\end{tabular}

IRR, Incidence Rate Ratio 